\title{
The Process of Acclimation to Chronic Hypoxia Leads to Submandibular Gland and Periodontal Alterations: An Insight on the Role of Inflammatory Mediators
}

\author{
Antonela Romina Terrizzi, ${ }^{1,2}$ María Inés Conti, ${ }^{1}$ María Pilar Martínez, ${ }^{1}$ \\ and Javier Fernández-Solari $\oplus^{1,2}$ \\ ${ }^{1}$ Cátedra de Fisiología, Facultad de Odontología, Universidad de Buenos Aires, Buenos Aires 1122, Argentina \\ ${ }^{2}$ CONICET, Consejo Nacional de Investigaciones Científicas y Técnicas, Buenos Aires 1122, Argentina \\ Correspondence should be addressed to Javier Fernández-Solari; javierfsolari@yahoo.com.ar
}

Received 4 June 2018; Revised 17 September 2018; Accepted 28 October 2018; Published 9 December 2018

Academic Editor: Tomasz Brzozowski

Copyright (c) 2018 Antonela Romina Terrizzi et al. This is an open access article distributed under the Creative Commons Attribution License, which permits unrestricted use, distribution, and reproduction in any medium, provided the original work is properly cited.

\begin{abstract}
The exposition to hypoxia is a stressful stimulus, and the organism develops acclimation mechanisms to ensure homeostasis, but if this fails, it leads to the development of pathological processes. Considering the large number of people under hypoxic conditions, it is of utmost importance to study the mechanisms implicated in hypoxic acclimation in oral tissues and the possible alteration of some important inflammatory markers that regulate salivary and periodontal function. It is the aim of the present study to analyze submandibular (SMG) and periodontal status of animals chronically exposed to continuous (CCH) or intermittent $(\mathrm{CIH})$ hypoxia in order to elucidate the underlying molecular mechanisms that may lead to hypoxic acclimation. Adult Wistar rats were exposed to $\mathrm{CCH}$ or $\mathrm{CIH}$ simulating 4200 meters of altitude during 90 days. Salivary secretion was decreased in animals exposed to hypoxia, being lower in $\mathrm{CIH}$, together with increased prostaglandin $\mathrm{E}_{2}$ ( $\mathrm{PGE}_{2}$ ) content, TBARS concentration, and the presence of apoptotic nuclei and irregular secretion granules in SMG. AQP-5 mRNA levels decreased in both hypoxic groups. Only the CCH group showed higher HIF-1 $\alpha$ staining, while $\mathrm{CIH}$ alone exhibited interradicular bone loss and increased concentration of the bone resorption marker CTX-I. In summary, animals exposed to CIH show a worse salivary secretion rate, which related with higher levels of $\mathrm{PGE}_{2}$, suggesting a negative role of this inflammatory mediator during hypoxia acclimation. We link the weak immunorreactivity of HIF- $1 \alpha$ in CIH with improper hypoxia acclimation, which is necessary to sustaining SMG physiology under this environmental condition. The alveolar bone loss observed in CIH rats could be due mainly to a direct effect of $\mathrm{PGE}_{2}$, as suggested by its higher content in gingival tissue, but also to the indirect effect of hyposalivation. This study may eventually contribute to finding therapeutics to treat the decreased salivary flow, improving in that way oral health.
\end{abstract}

\section{Introduction}

Saliva is a mixed fluid that derives predominantly from 3 pairs of major salivary glands: the submandibular (SMG), the parotid, and the sublingual glands, producing 70, 20, and $5 \%$ of whole saliva, respectively $[1,2]$. The secretion of saliva is controlled by the autonomic nervous system. The parasympathetic nervous system is the main controller of this secretion via impulses in the chorda tympani nerve that innervate it and release acetylcholine, which evokes copious salivary secretion by activating muscarinic receptors. The sympathetic nervous system controls salivary secretion by also acting on $\alpha$ - and $\beta$-adrenergic receptors, inducing less volume of thicker saliva. Although the salivary flow is regulated by autonomic reflexes, there are other substances that play an important role in the salivary secretion rate. An increased level of prostaglandin $\mathrm{E}_{2}\left(\mathrm{PGE}_{2}\right)$ has been associated with decreased salivary output whereas nitric oxide (NO) is considered to be a potent stimulator of salivary secretion [3]. Saliva represents the first barrier to the entry of 
bacteria and viruses into the body, and thus, changes in its secretion are important in the statement and progression of oral infectious processes [4]. Diminished salivary output is called "hyposalivation" and significantly affects the individual's quality of life as well as oral health $[1,5]$ as mechanical cleansing, lubrication, tooth mineralization, and antimicrobial activity are affected. Besides these functions, salivary glands are known to act as immunomodulatory organs that regulate immune/inflammatory reactions within the oral environment [6].

Hypoxemic hypoxia can be defined as a condition wherein the oxygen pressure in the blood is too low to saturate hemoglobin. This type of hypoxia is due to two mechanisms: (1) a decrease in the amount of breathable oxygen due to reduced barometric pressure [7], often encountered in pilots, mountain climbers, and people living at high altitude, and (2) cardiopulmonary failure in which the lungs are unable to efficiently transfer oxygen from the alveoli to the blood. In the case of people inhabiting at high altitude, they are considered to be exposed to chronic continuous hypoxia $(\mathrm{CCH})$ and they represent $2 \%$ of the world's population [8]. However, there is another frequent condition of exposition to hypoxia that is not continuous (mountain sports, laboral activities, and diseases such as sleep apnea), known as intermittent hypoxia [9]. The exposition to hypoxia is considered to be a stressful stimulus, and the organism has to develop physiological compensatory mechanisms to ensure homeostasis. Acclimation is the most prevalent phenotypic modification that takes place under hypoxia and involves hematological, cardiovascular, renal, and metabolic changes to help the organism to cope with lower $\mathrm{O}_{2}$ levels [10]. At a molecular level, hypoxia evokes highly coordinated cellular responses in order to preserve cell viability. These adaptive responses are orchestrated by the hypoxia-inducible factors (HIFs), "master" regulators of the hypoxic response [11]. The mechanisms that take place under $\mathrm{CCH}$ conditions are different compared to intermittent exposure, mainly because of the distinct signaling pathways activated due to the length and intervals of lower $\mathrm{O}_{2}$ partial pressure [9]. Despite that the adaptive response is aimed at helping the organism to cope with low oxygenation, hypoxia could also lead to the development of pathological processes if the ability to maintain $\mathrm{O}_{2}$ homeostasis fails [12]. It has been accepted that hypoxia is able to induce inflammation. Hypoxia amplifies several molecular pathways that are involved in phagocytosis, leukocyte recruitment, and adaptive immunity, meaning that the activation of HIF- $1 \alpha$ is necessary to eliminate pathogens [13]. Besides, hypoxia exposure is known to increase cellular oxidative stress leading to the production of reactive oxygen species (ROS) with deleterious effects on lipids, proteins, and DNA [14].

Despite the fact that the effects of hypoxia in the organism are well established, its role on oral health is still not clear. In the salivary gland research field, hypoxia has been shown to decrease salivary secretion in submandibular glands [15]. The mechanisms by which it may induce hyposalivation are still unclear, as the role of HIF- $1 \alpha$ in acinar cells has not been yet elucidated. Sugimoto et al. [16] reported that aquaporins $(\mathrm{AQP})$, proteins that control water secretion and play an important role during the first step of saliva synthesis, were regulated by HIF, suggesting a possible mechanism by which hypoxia could decrease the salivary flow rate. As mentioned previously, an imbalance in $\mathrm{NO}$ or $\mathrm{PGE}_{2}$ production could also be linked with decreased saliva volume.

On the other hand, the periodontal field is the one that has received major contributions on the topic. It is known that hypoxic exposure increases alveolar bone loss in rats both with and without experimental periodontitis [17], as well as the level of some important inflammatory mediators during periodontitis pathogenesis, such as $\mathrm{NO}$ and tumor necrosis factor $\alpha$ [17-19]. However, there is no study that compares alveolar bone loss under the two different types of hypoxic exposition.

The limited $\mathrm{O}_{2}$ attained during exposure to chronic hypoxia acts as a challenging stimulus and, considering the large number of people under these circumstances, together with the possible alteration of some important inflammatory markers that regulate salivary and periodontal function under hypoxia, makes it of utmost importance to study the mechanisms implicated in acclimation in oral tissues. Therefore, the aim of the present study was to evaluate the salivary gland and alveolar bone status of rats submitted to chronic continuous hypoxia in order to elucidate the underlying molecular mechanisms that may lead to hypoxic acclimation.

\section{Methods}

2.1. Experimental Design. Adult female Wistar rats (initial weight $250 \mathrm{~g}$ ) were used throughout the experiments. They were weighted and randomly divided into 3 groups of 12 animals each as follows: control (C; normoxic environment), chronic continuous hypoxia $(\mathrm{CCH}$; continuously exposed to 600 mbar, which equals $4200 \mathrm{~m}$ of altitude above sea level, placing the animals into a simulated high-altitude chamber $24 \mathrm{~h} / 7$ days a week), and chronic intermittent hypoxia ( $\mathrm{CIH}$; exposed to $18 \mathrm{~h} / 5$ days a week to $600 \mathrm{mbar}$ ). These hypoxic schemes were chosen due to the fact that intermittent exposed animals are submitted to the hypoxic stress half the time than the continuous exposed animals, as suggested by other authors in the literature $[9,20]$. All animals were allowed free access to water and a standard pelleted chow diet and were treated in accordance with the National Institutes of Health guidelines for the care and use of laboratory animals (NIH 8th edition, 2011). Protocols were approved by the Ethical Commission of the Faculty of Dentistry, University of Buenos Aires (no. 11/06/2012-23). At the end of the experimental period ( 3 months), animals were euthanized by $\mathrm{CO}_{2}$ and weighed. Both hemimandibles and SMG were collected to perform biochemical and histological determinations. Blood samples were taken by cardiac puncture to verify the hypoxic state assessing the hematocrit (\%) by micromethod [21].

2.2. Salivary Secretion Rate. Two weeks before the autopsy, animals were anesthetized with $2 \%$ of xylazine chloride ( $5 \mathrm{mg} / \mathrm{kg}$; i.p.) and $5 \%$ ketamine chloride (50 mg/kg, i.p.) to assess salivary secretion by collecting and weighing salivary samples after stimulation with pilocarpine $(0.5 \mathrm{mg} / \mathrm{kg}$, in 
saline). Briefly, a cotton ball of $20 \mathrm{mg}$ was placed inside the rat's cheek to collect saliva and weighed at the end of 30 , 60 , and 90 minutes, obtaining 3 measurements of each animal at 3 different time points [22].

\subsection{Inflammatory Mediators in SMG and Gingival Tissue}

2.3.1. Radioimmunoassay (RIA) of $P G E_{2}$. To evaluate $\mathrm{PGE}_{2}$ content, SMG or gingiva was homogenized in ice-cold ethanol (100\%) and centrifuged at $10,000 \mathrm{x}$ g for $15 \mathrm{~min}$ at $4^{\circ} \mathrm{C}$, and the supernatant was collected and evaporated in a SpeedVac. The residues were resuspended with RIA buffer, and the Sigma antiserum was used. The $\mathrm{PGE}_{2}$ content was expressed as $\mathrm{pg} / \mathrm{mg}$ of weight tissue [23].

2.3.2. Measurement of Inducible Nitric Oxide Synthase (iNOS) Activity. The activity of iNOS was measured by modifying the method of Bredt \& Snyder [24]. SMG was homogenized separately in $500 \mu \mathrm{l}$ of ice-cold $20 \mathrm{mM}$ HEPES (pH 7.4; Sigma-Aldrich) with EGTA $(2 \mathrm{mM})$ and DL-dithiothreitol (DTT, $1 \mathrm{mM}$; Sigma-Aldrich). After the tissue was homogenized, NADPH (120 $\mu \mathrm{M}$; Sigma-Aldrich) and 200,000 dpm of [14C]-arginine monochloride $(297 \mathrm{mCi} / \mathrm{mmol}$; PerkinElmer, Waltham, MA, USA) were added to each tube and incubated for $10 \mathrm{~min}$ at $37^{\circ} \mathrm{C}$ in a Dubnoff metabolic shaker (50 cycles per $\min ; 95 \% \mathrm{O}_{2} / 5 \% \mathrm{CO}_{2}$ ) at $37^{\circ} \mathrm{C}$. The tubes were then centrifuged at $10,000 \mathrm{x}$ for $10 \mathrm{~min}$ at $4^{\circ} \mathrm{C}$. The supernatants were applied to individual columns containing $1 \mathrm{ml}$ of Dowex AG 50W-X8 $\mathrm{Na}^{+}$form mesh 200-400 (Bio-Rad Laboratories, Hercules, CA, USA) and washed with $2.5 \mathrm{ml}$ of double-distilled water. All collected effluent fluid from each column was counted for activity of [14C]-citrulline in a liquid scintillation analyser (Tri-Carb 2800TR, PerkinElmer). Since NOS converts arginine into equimolar quantities of $\mathrm{NO}$ and citrulline, the data were expressed as pmol of NO produced per min per mg of protein [25].

2.3.3. TBARS Content. Thiobarbituric acid-reactive substances (TBARS) were evaluated in SMG quantifying malondialdehyde (MDA) as the product of lipid peroxidation that reacts with trichloroacetic acid- $\mathrm{HCl}$, yielding a pink-stained TBARS determined in a spectrophotometer (Hitachi U$2001)$ at $540 \mathrm{~nm}$. TBARS were calculated as nanomoles per milligram of tissue [26].

\subsection{Histological and Immunohistochemical Analyses}

2.4.1. Optic Microscopy. A portion of SMG was fixed in a $4 \%$ formaldehyde- phosphate saline (PBS) buffer solution, embedded in paraffin, and cut into $5 \mu \mathrm{m}$ sections to perform routine histologic analyses with hematoxylin and eosin (H\&E) staining and immunohistochemistry. After dewaxing and rehydration, slides were submitted to antigen retrieval with citrate buffer $\mathrm{pH} 6$ for 10 minutes in a microwave oven followed by 20 minutes of peroxide blocking reagent exposure (EnVision ${ }^{\mathrm{TM}}$ FLEX Systems FLEX, Dako, USA) to block endogenous peroxidase activity. Nonspecific protein binding was blocked using 3\% bovine serum albumin (BSA) in PBS. Afterwards, sections were stained with primary antibodies (anti-HIF- $1 \alpha$ or anti-AQP-5; Biorbyt, UK) at $4^{\circ} \mathrm{C}$ overnight followed by exposure to horseradish peroxidase-conjugated secondary antibody (EnVision ${ }^{\mathrm{TM}}$ FLEX Systems Dako). A brown chromogen was used to detect the primary antibody, and hematoxylin was used as a counterstain [27].

2.4.2. Transmission Electron Microscopy. Ultrastructural analyses of SMG morphology were done by transmission electron microscopy (TEM). Briefly, tissue blocks of approximately $1 \mathrm{~mm}^{3}$ were fixed in $1 \%$ glutaraldehyde in $0.1 \mathrm{M}$ phosphate buffer ( $\mathrm{pH} 7.4$ ) for 4 hours and then washed 3 times with $0.1 \mathrm{M}$ phosphate buffer. After dehydration and embedding in Durcupan resin (Fluka AG, Switzerland), tissue sections of $5 \mathrm{~nm}$ were cut and stained with uranyl and lead citrate. Sections were observed under a Zeiss EM 109T transmission electron microscope.

2.5. $m R N A$ Levels of HIF- $1 \alpha$ and AQP-5 in SMG. Pieces of SMG of approximately $50 \mathrm{mg}$ were homogenized with RNAzol Reagent and stored at $-80^{\circ} \mathrm{C}$ until used. RNA was extracted according to the manufacturer's indications (Molecular Research Center Inc., Cincinnati, OH, USA) and quantified by NanoDrop (Eppendorf, Hamburg, Germany). Afterwards, cDNA was synthesized from total RNA (3 $\mu \mathrm{g}$ ) using M-MLV RT, ribonuclease inhibitor, and random primers. The specific primers were designed using Primer 3 Software, and the sequences were $\beta$-actin: forward $5^{\prime}$ ACCC GCCGAGTACAACCTTC $3^{\prime}$ and reverse $5^{\prime}$ ATGCCGTGT TCAATGGGGTA $3^{\prime}\left(94^{\circ} \mathrm{C} 5 \mathrm{~min} ; 35\right.$ cycles of $94^{\circ} \mathrm{C} 40 \mathrm{~s}$, $58^{\circ} \mathrm{C} 30 \mathrm{~s}$, and $72^{\circ} \mathrm{C} 1 \mathrm{~min}$; and $72^{\circ} \mathrm{C} 5 \mathrm{~min}$ ) product (bp): 156; AQP-5: forward $5^{\prime}$ GAGATTCGTGAATGCGGTGC3' and reverse $5^{\prime}$ GTGGTTTATTGGGAAGCGCC $3^{\prime} \quad\left(94^{\circ} \mathrm{C}\right.$ $5 \mathrm{~min} ; 35$ cycles of: $94^{\circ} \mathrm{C} 40 \mathrm{~s}, 62^{\circ} \mathrm{C} 30 \mathrm{~s}$, and $72^{\circ} \mathrm{C} 1 \mathrm{~min}$; and $72^{\circ} \mathrm{C} 5 \mathrm{~min}$ ), product (bp) 256; HIF-1 $\alpha$ : forward $5^{\prime}$ TGCTTGGTGCTGATTTGTGA $3^{\prime}$ and reverse $5^{\prime}$ GGTC AGATGATCAGAGTCCA3 ${ }^{\prime}\left(94^{\circ} \mathrm{C} 5 \mathrm{~min} ; 35\right.$ cycles of $94^{\circ} \mathrm{C} 40 \mathrm{~s}, 55^{\circ} \mathrm{C} 30 \mathrm{~s}$, and $72^{\circ} \mathrm{C} 1 \mathrm{~min}$; and $72^{\circ} \mathrm{C} 5 \mathrm{~min}$ ) product (bp) 210. Products were loaded onto $2 \%$ agarose gel, and bands were visualized on a transilluminator under UV light. Photographs were taken with a digital camera (Olympus C-5060) and analyzed with the ImageJ software package. The relative mRNA level was normalized to $\beta$ actin, and results were expressed as arbitrary units (AU) of relative optical density [28].

\subsection{Alveolar Bone Loss Determinations}

2.6.1. Cortical Bone Loss by Distance Method. Hemimandibles were resected, defleshed, and stained with $1 \%$ aqueous methylene blue to delineate the cement-enamel junction (CEJ) and the alveolar crest (AC) [29]. A stereomicroscope and a digital caliper were used to measure three buccal and three lingual distances (mesial, central, and distal), from the CEJ to the AC. The sum of the three distances of each side of molars was used as a measure of the alveolar bone loss in millimeters.

2.6.2. Interradicular Bone Loss. Hemimandibles were fixed in formalin buffer. Afterwards, they were decalcified in $10 \%$ EDTA pH 7 for 45 days, dehydrated with ethyl alcohol, and 
TABLE 1: Hematocrit and morphometrical measurements. Body weight (g), SMG weight (mg), and hematocrit (\%) in control (C), chronic intermittent hypoxia- (CIH-), and chronic continuous hypoxia- $(\mathrm{CCH}-)$ exposed animals. Results are expressed as mean \pm SEM. Statistics: $a \neq b \neq c, p<0.05$.

\begin{tabular}{lccc}
\hline & Control & CIH & CCH \\
\hline Body weight $(\mathrm{g})$ & $357.20 \pm 31.33^{\mathrm{a}}$ & $320.41 \pm 21.41^{\mathrm{a}}$ & $337.08 \pm 17.60^{\mathrm{a}}$ \\
SMG weight $(\mathrm{mg})$ & $218.16 \pm 16.40^{\mathrm{a}}$ & $198.20 \pm 10.86^{\mathrm{a}}$ & $192.87 \pm 21.17^{\mathrm{a}}$ \\
Hematocrit $(\%)$ & $53.10 \pm 4.18^{\mathrm{a}}$ & $61.09 \pm 5.74^{\mathrm{b}}$ & $68.52 \pm 5.03^{\mathrm{c}}$ \\
\hline
\end{tabular}

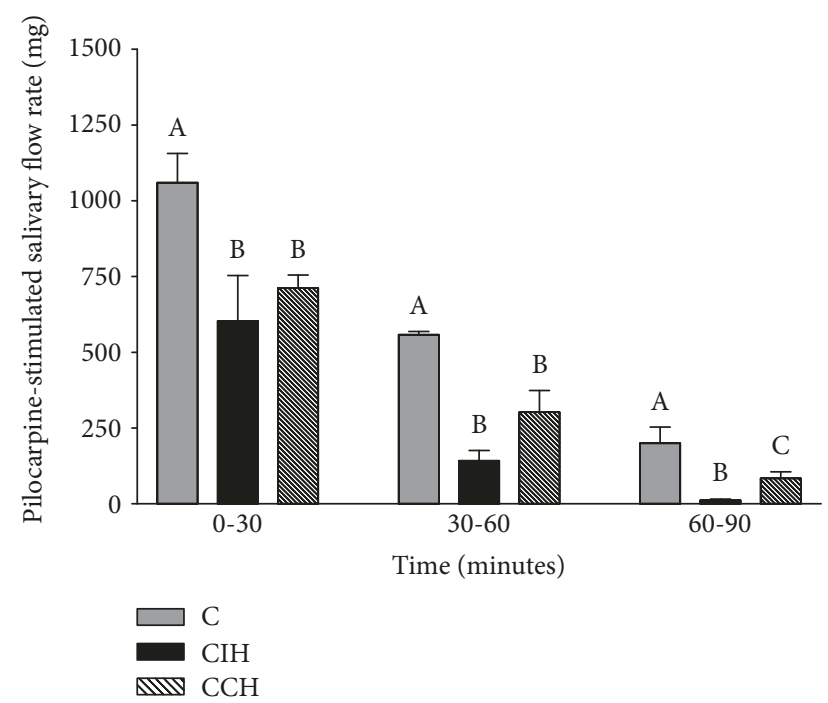

FIGURE 1: Effect of hypoxia on total salivary response to pilocarpine. $\mathrm{C}$ : control; $\mathrm{CIH}$ : chronic intermittent hypoxia; $\mathrm{CCH}$ : chronic continuous hypoxia. Results are presented in mean \pm SEM. Statistics: $a \neq b \neq c, p<0.05$.

clarified with xylene. The sector containing the first molar was embedded in paraffin, and $7 \mu \mathrm{m}$ sections of each first molar oriented mesiodistally were obtained and stained with H\&E. Histomorphometric evaluation was performed on digitalized microphotographs using Image-Pro Plus 4.5 software. Interradicular bone volume was measured as bone volume (BV)/total volume (TV) (\%). TV was taken as bone tissue plus bone narrow and periodontal ligament [30]. Histopathological analyzed of the gum tissue around the first molar was also performed.

2.6.3. C-Terminal Telopeptide of Collagen Type I (CTX-I) Concentration. The concentration of this bone resorption marker was determined in serum by using an ELISA commercial kit, following the manufacturer's instructions (Fine Test, Wuhan Fine Biotech Co., Wuhan, China).

\section{Statistics}

Experiments were performed at least three times, and figures represent results of individual experiments. Data were expressed as mean \pm SEM. Analysis of variance followed by Tukey's test for multiple comparisons was used to determine statistical significance $(p<0.05)$. Statistical analysis was performed using the software InfoStat (Córdoba, Argentina).

\section{Results}

4.1. Hematocrit and Morphometric Measures. At the end of the experimental period, body and SMG weight were determined. These morphometric measures were not statistically different among groups. As all the animals ate the same amount of food, we consider that the changes in the parameters further described in SMG would not be due to nutritional state. To verify the hypoxic state, hematocrit was assessed. Increased values were found in both hypoxic groups compared with control animals, being higher in continuous exposed rats (15\% higher in $\mathrm{CIH}$ vs. $29 \%$ higher in $\mathrm{CCH}$ ) (Table 1).

4.2. Exposition to Chronic Hypoxia Decreases Total Salivary Flow Rate, Mainly during Intermittent Exposure. In order to explore the effects of hypobaric hypoxia on salivary flow, pilocarpine was used to stimulate salivary secretion. Total collected saliva was decreased in both hypoxic groups within the first $30 \mathrm{~min}$ of stimulation compared to C (ANOVA $F$ ( $2,13)=4.88, p<0.05)$. After $60 \mathrm{~min}$, the same pattern was observed, but salivary secretion was lower against $\mathrm{C}$ in intermittently exposed animals $(75 \%$ in $\mathrm{CIH} ; p<0.01$ vs. $46 \%$ in $\mathrm{CCH}$; ANOVA $F(2,13)=12.47, p<0.05)$, without statistical difference between both hypoxic animals. After $90 \mathrm{~min}$, total salivary secretion in $\mathrm{CIH}$ was $95 \%$ lower than $\mathrm{C}$ animals and in $\mathrm{CCH}$ the amount of saliva was $59 \%$ lower than $\mathrm{C}$, with existing statistical difference in both hypoxic groups (ANOVA $F(2,12)=5.62, p<0.05)$ (Figure 1$)$. In summary, this study reflects a lower salivary secretion rate in animals exposed to hypoxia, with secretion being more impaired during intermittent exposure.

4.3. PGE $E_{2}$ Content and TBARS Concentrations in SMG Are Enhanced during Chronic Hypoxia. To understand the link between prostaglandins and salivary secretion, $\mathrm{PGE}_{2}$ content was measured, as a negative correlation between $\mathrm{PGE}_{2}$ content and salivary function has been established [3]. CIH significantly increased $\mathrm{PGE}_{2}$ content compared to both control and $\mathrm{CCH}$ (Figure 2(a)) (ANOVA, F $(2,12)=6.85$, $p<0.05)$. The activity of iNOS was also analyzed, as nitric oxide derived from this enzyme is a potentially significant factor altering salivary secretion in conditions that affect SMG. No statistical difference in iNOS activity was found between control and both hypoxic groups (Figure 2(b)) (ANOVA, $F(2,14)=0.30, p>0.05)$. Since oxidative stress 


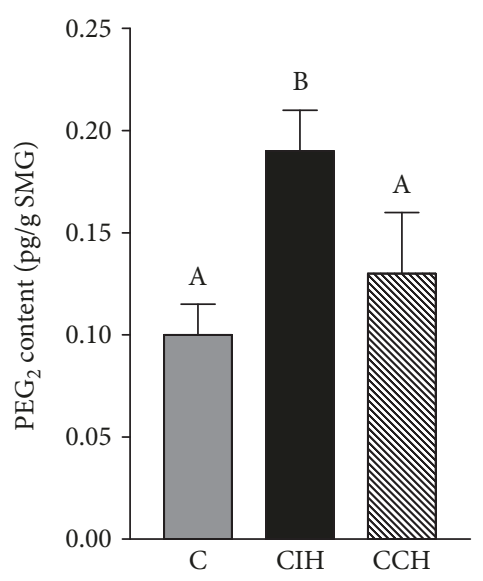

(a)

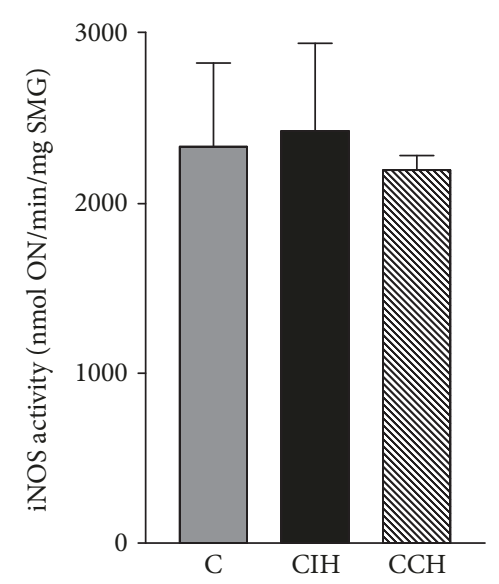

(b)

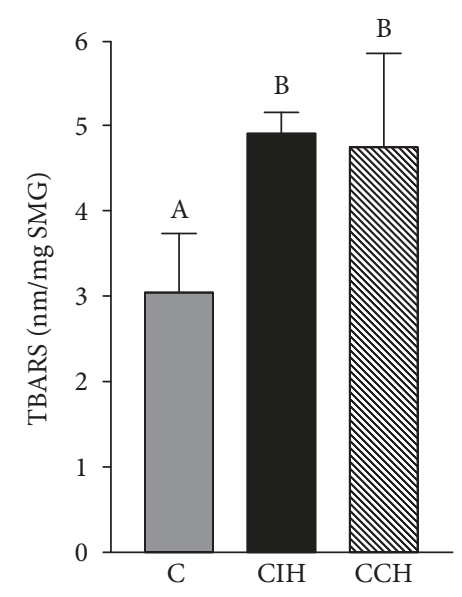

(c)

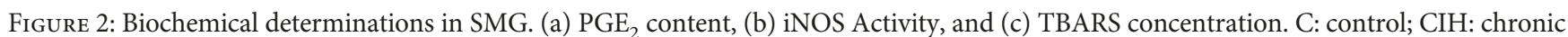
intermittent hypoxia; $\mathrm{CCH}$ : chronic continuous hypoxia. Results are presented in mean \pm SEM. Statistics: $a \neq b \neq c, p<0.05$.

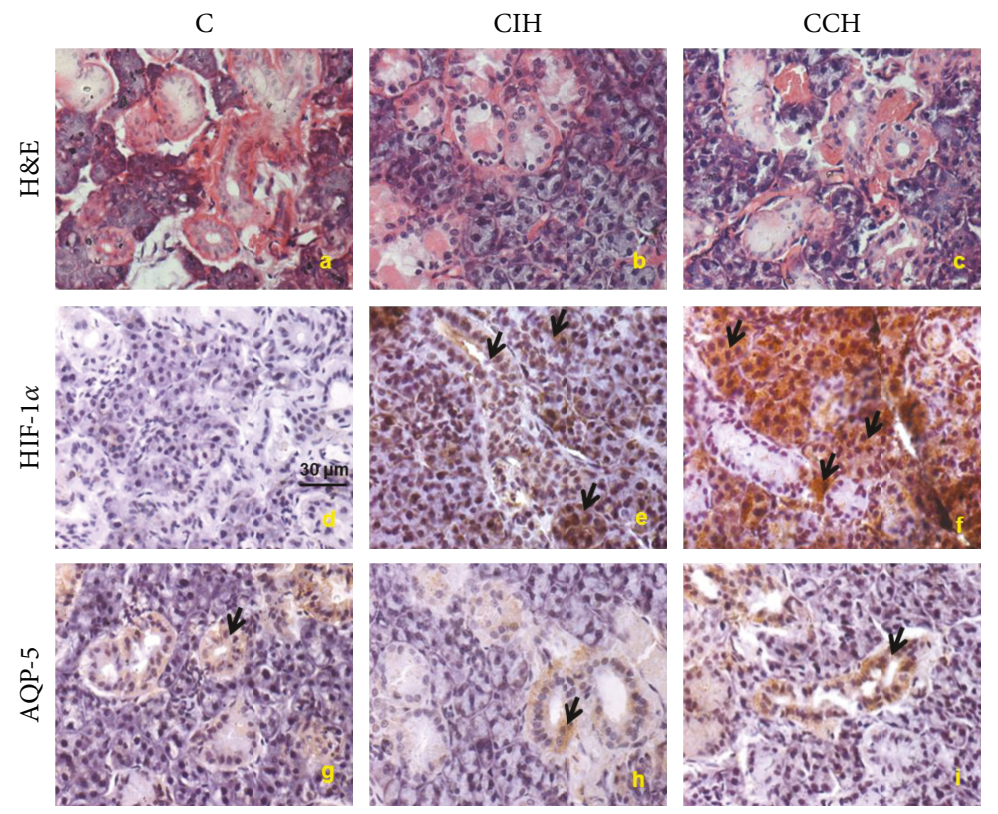

FIGURE 3: Histological analyses of SMG. Photographs of SMG of one randomly selected slide per group. Resected SMG were observed under a Zeiss Axiophot microscope (40x). Scale bar $=30 \mu \mathrm{m}$. C: control; CIH: chronic intermittent hypoxia; CCH: chronic continuous hypoxia. SMG stained with H\&E (a, b, and c). HIF- $1 \alpha$ (d, e, and f) immunohistochemistry. AQ-5 immunoreactivity (g, h, and i) $n=6$ animals per group. Arrows indicate HIF- $1 \alpha$ and AQP-5-positive cells.

is known to be a hallmark of hypoxia-mediated tissue damage, TBARS were assessed in SMG. Both types of exposure significantly enhanced TBARS content in SMG (Figure 2(c)), suggesting the existence of lipid peroxidation in the gland (ANOVA, $F(2,15)=5.81, p<0.05)$.

\subsection{Intermittent Hypoxia Induces Ultrastructural Alterations} in $S M G$. Regarding routine histological analyses in SMG, no parenchymal or stromal changes were observed in any group (Figures 3(a)-3(c)). However, electronic microscopy analyses revealed apoptotic cells in acini and intercalated ducts and irregular and fewer secretory granules in acini of SMG of the $\mathrm{CIH}$-exposed group. Normal epithelial cell morphology was observed in serous and mucous acini of the $\mathrm{C}$ and HCC groups (Figures 4(a) and 4(b)).

4.5. Higher HIF-1 $\alpha$ Immunorreactivity Was Observed in SMG of $\mathrm{CCH}$ Animals. RT-PCR studies revealed that HIF- $1 \alpha$ mRNA levels in SMG were higher in both hypoxic groups compared to $\mathrm{C}$ (whose level was not detectable), but there were no statistical differences between $\mathrm{CIH}$ and $\mathrm{CCH}$ (ANOVA $F(2,12)=27.75, p<0.05) \quad($ Table 2). When 

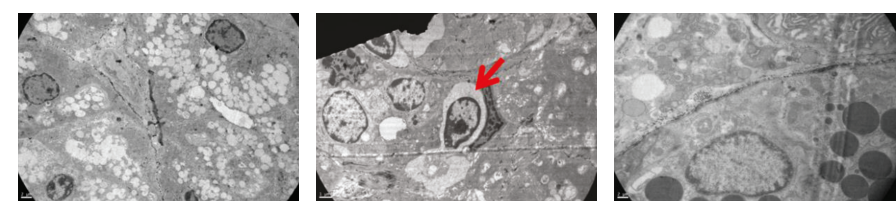

(a)
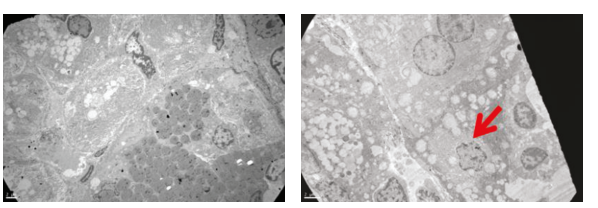

(b)

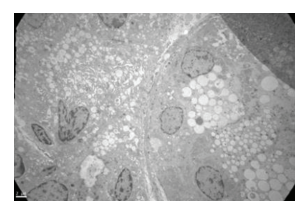

FIgURe 4: Ultrastructural analyses of SMG. Photographs of SMG of one randomly selected slide per group observed under a Zeiss EM 109T (3000x). Scale bar $=2 \mu \mathrm{m}$. C: control; $\mathrm{CIH}$ : chronic intermittent hypoxia; $\mathrm{CCH}$ : chronic continuous hypoxia. (a) Acini and (b) intercalated ducts. Arrows indicate apoptotic nuclei.

TABLE 2: AQP-5 and HIF- $1 \alpha$ mRNA expression. Results are expressed as relative optical density in arbitrary units (AU) and normalized to $\beta$ actin mRNA expression. Statistics: $a \neq b \neq c, p<0.05$. n/d: nondetectable.

\begin{tabular}{lccc}
\hline mRNA levels in SMG (AU) & Control & CIH & CCH \\
\hline AQP-5/ $\beta$-actin & $5.39 \pm 0.89^{\mathrm{a}}$ & $2.31 \pm 0.64^{\mathrm{b}}$ & $1.95 \pm 0.75^{\mathrm{b}}$ \\
HIF- $1 \alpha / \beta$-actin & $\mathrm{n} / \mathrm{d}^{\mathrm{a}}$ & $1.72 \pm 0.51^{\mathrm{b}}$ & $1.31 \pm 0.42^{\mathrm{b}}$ \\
\hline
\end{tabular}

analyzing the localization of HIF- $1 \alpha$ by immunohistochemistry, we found, as expected, lack of staining in the $\mathrm{C}$ group. SMG of animals exposed to hypoxia showed higher immunorreactivity of this transcription factor in the cytoplasm, mainly in serous acini and ducts, with low or no color in mucous acini. SMG of the $\mathrm{CIH}$ group showed irregular staining, with areas of no expression similar to the $\mathrm{C}$ group. Only the glands of the $\mathrm{CCH}$ group showed homogeneous increase in HIF-1 $\alpha$ immunorreactivity (Figures $3(\mathrm{~d})-3(\mathrm{f})$ ).

4.6. Hypoxia Diminished AQP-5 mRNA Levels in SMG. It has been shown that alteration in AQP-5 expression may lead to hyposecretion in salivary glands. In our present study, exposition to hypoxia decreased mRNA levels of AQP-5 in SMG of both hypoxic groups, suggesting that this could be a possible explanation for the impaired salivary flow in salivary glands of hypoxic rats (ANOVA $F(2,12)=29.48, p<0.05$ ) (Table 2). However, immunohistochemical analyses of AQP-5 revealed no significant changes in its localization or immunorreactivity due to hypoxia. Staining was localized mainly in intercalated ducts and mucous acini, with no immunorreactivity in serous acini (Figures 3(g) $-3(\mathrm{i})$ ).

4.7. Intermittent Hypoxia Exposure Increased Cortical and Interradicular Alveolar Bone Loss. To assess alveolar bone loss, both cortical and interradicular bone was measured. Both hypoxic groups showed increased cortical bone loss at the lingual side of the mandible (ANOVA $F(2,15)=54.50$, $p<0.05$ ) (Figure 5(a)) as determined by the distance method. When interradicular bone volume was analyzed, we found that only $\mathrm{CIH}$ significantly enhanced this parameter (ANOVA $F(2,12)=4.70, p<0.05)$ and increased bone marrow cavity when compared to $\mathrm{C}$ and $\mathrm{CCH}$-exposed animals (Figure 5(b)). A higher content of $\mathrm{PGE}_{2}$ was found in gingival tissue surrounding the lower first molar only in CIH (Figure 6(a)). With this molecule being a known stimulator of bone loss during periodontal disease [21], we can link the observed bone loss in intermittent exposed animals to the increased levels of this inflammatory mediator. When analyzing gingival tissue by optic microscopy, we found no evidence of inflammatory response. Both epithelial and connective tissue showed normal structures in gums of the 3 groups (Figure 6(b)). Furthermore, only the $\mathrm{CIH}$ group showed increased concentration of CTX-I in serum, indicating increased bone turnover (ANOVA $F(2,31)=12.03, p<0.05)$ (Figure 7 ).

\section{Discussion}

Salivary glands are key organs in the regulation of hydric, mineral, and immunologic balance of the oral environment [31]. Besides its mechanic cleansing effect, saliva also exerts a role in mucosal host defense thanks to the presence of secretory immunoglobulin and many antimicrobial proteins. A decrease in salivary flow and/or an alteration in saliva composition lead to bacterial overgrowth and increased inflammatory response, which may contribute to pathological bone resorption and tissue detachment observed in periodontal disease [6]. In this study, we show that exposure to chronic hypoxia impairs salivary gland secretion. Intermittent exposure seems to be more detrimental than continuous exposition, as a 95\% decrease in salivary secretion was observed after 90 minutes of pilocarpine stimulation vs. 59\% decrease in $\mathrm{CCH}$. Other authors have reported studies dealing with salivary flow in animals or humans submitted to high altitude $[15,32]$, but none of these studies were performed chronically at altitudes where human life can 

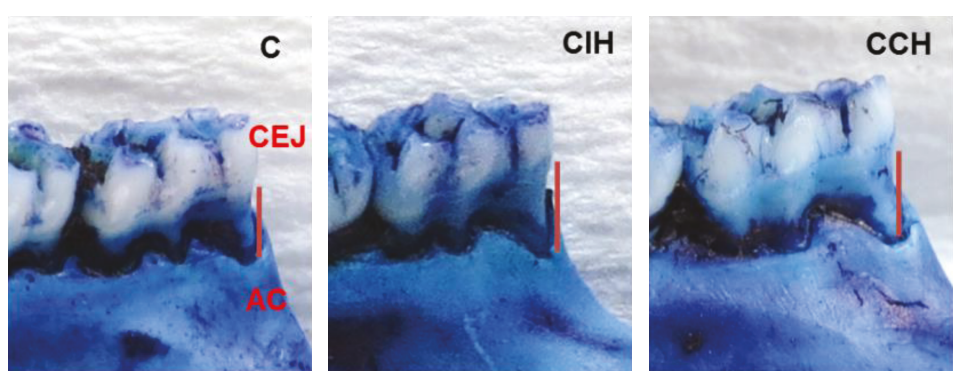

(a)
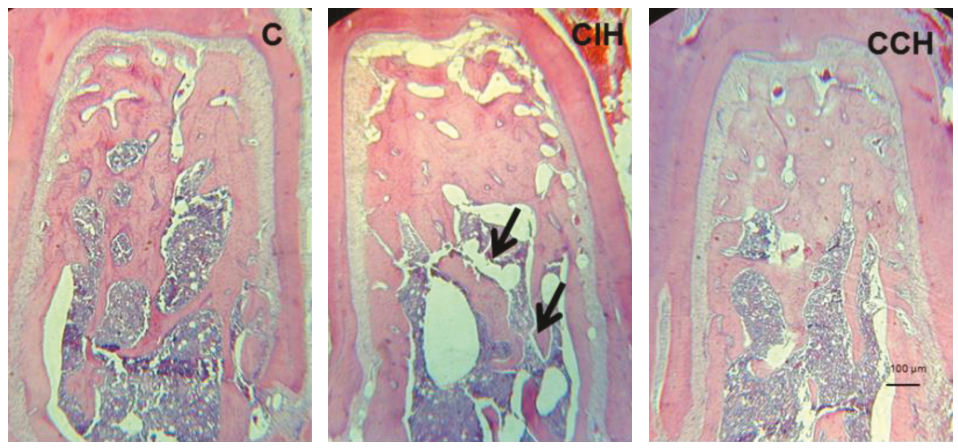
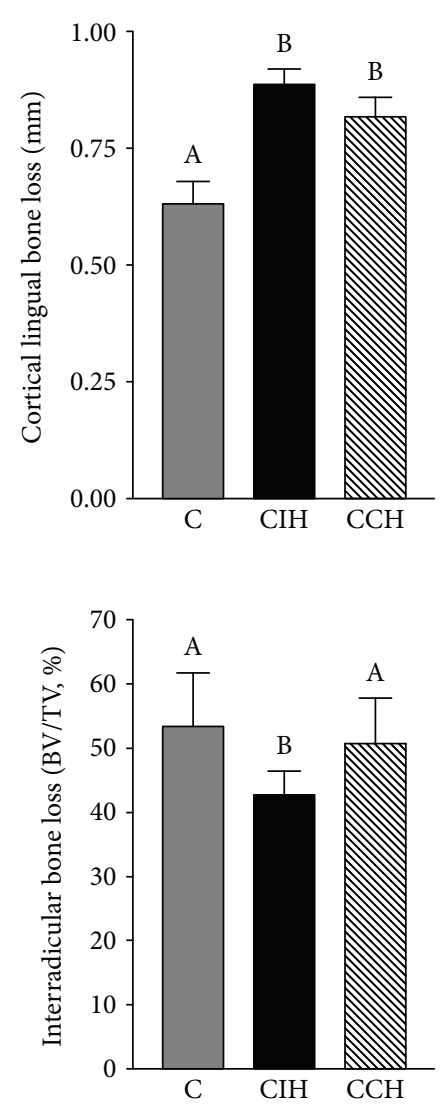

(b)

FIGURE 5: Cortical and interradicular alveolar bone loss assessment. (a) Lingual bone loss (mm). Photographs of the lingual side of the mandible in the lower first molar region of one animal per group selected randomly. (b) Interradicular bone loss (BV/TV, \%). Photographs of transverse slides of the longitudinal sections of the mandibular interradicular bone in $\mathrm{C}$ (control), $\mathrm{CIH}$ (chronic intermittent hypoxia), and $\mathrm{CCH}$ (chronic continuous hypoxia) of one animal per group selected randomly $(2.5 \mathrm{x})$. Scale bar $=100 \mu \mathrm{m}$. Results are presented in mean \pm SEM. Statistics: $a \neq b \neq c, p<0.05$.

develop. That is to say, the hypoxic conditions selected for this study that simulate 4200 meters above sea level are the ones in which humans can develop acclimation mechanisms to compensate the low values of $\mathrm{O}_{2}$.

To understand the mechanisms of the effect observed in salivary secretion, many factors should be analyzed. First, morphometric differences of the organ among animals of the experimental groups, such as size and weight, should be ruled out. In the model used in this study, both corporal and submandibular gland weights were statistically equal in the three groups. This is related to the fact that adult animals ate the same amount of food in control and experimental conditions, allowing them to grow and develop similarly. Previously reported studies from our laboratory had shown that the development of growing rats was affected by hypoxia $[17,21,30]$, the reason why this study was planned with adult animals.

Secondly, prostaglandins in SMG have been reported by other authors as modulatory molecules leading to salivary response inhibition [3,22]. We observed increased levels of $\mathrm{PGE}_{2}$ in SMG of CIH-exposed rats, which would explain the severe hyposalivation observed after 90 minutes of pilocarpine stimulation. This result could be associated with a 


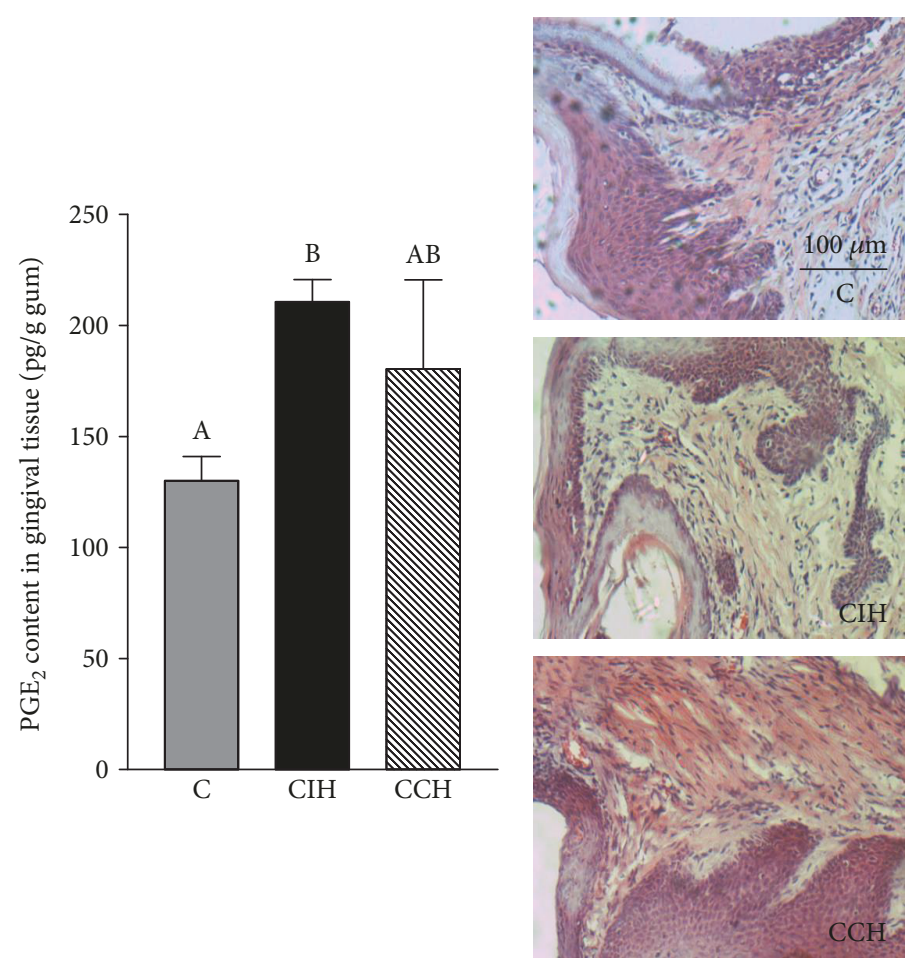

(a)

(b)

FIgURE 6: $\mathrm{PGE}_{2}$ content and histomorphometrical analyses in gum tissue. (a) $\mathrm{PGE}_{2}$ content in gingival tissue of animals exposed to CIH (chronic intermittent hypoxia) and $\mathrm{CCH}$ (chronic continuous hypoxia). Results are presented in mean \pm SEM. Statistics: $a \neq b \neq c$, $p<0.05$. (b) Photograph of the gingival tissue surrounding the lower first molar of one animal per group selected randomly (40x). Scale bar $=100 \mu \mathrm{m}$.

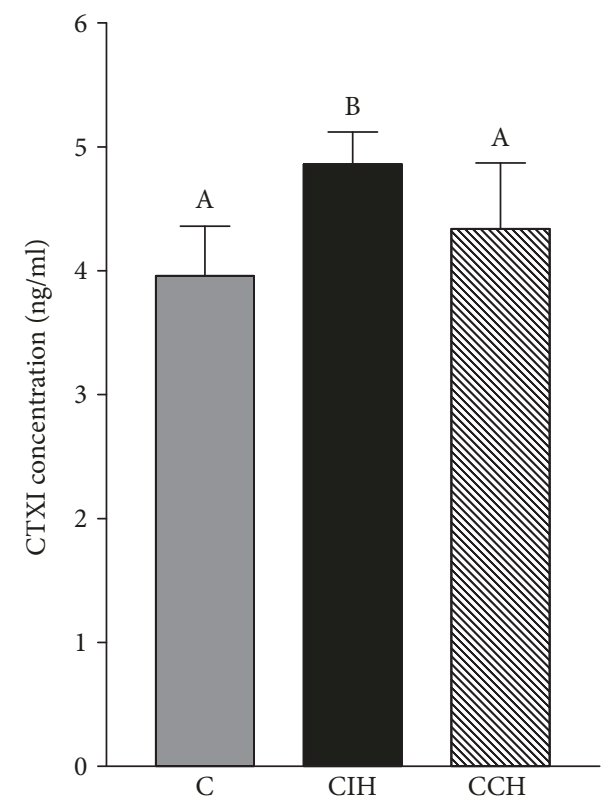

FIGURE 7: CTX-I concentration in serum. CIH (chronic intermittent hypoxia) and $\mathrm{CCH}$ (chronic continuous hypoxia). Results are presented in mean \pm SEM. Statistics: $a \neq b \neq c, p<0.05$.

with the decreased salivary flow observed. Impaired salivary secretion was further evaluated by the analysis of AQP-5. As aquaporins are molecules involved in transcellular water transport in salivary glands, their participation in the secretion rate is essential [37]. Under resting conditions, salivary glands maintain basal saliva secretion, while upon demand upregulation of the secretion is achieved by autonomic innervation. Parasympathetic stimulus through acetylcholine induces translocation of AQP-5 from intracellular vesicles to the apical membrane, allowing their function as water channels [38]. In several pathophysiological conditions, such as Sjögren syndrome, radiation therapy, diabetes, and senescence AQP-5 are reported to be downregulated or with a different localization [37], all of which correlate with reduced salivary secretion. On the other hand, the activation of HIF- $1 \alpha$ during hypoxia has been associated with the upregulation of aquaporin, leading to a compensatory increase in water transportation in many organs $[16,39]$. In the experimental setting of this study, no significant differences regarding AQP-5 distribution or localization were observed in the SMG of any experimental groups. However, the exposition to hypoxia decreased AQP-5 mRNA levels in the gland, suggesting that this molecule expression may be downregulated in this experimental model. In the case of hypoxia, the upregulation of AQP-5 mediated by the parasympathetic nervous system could be affected, as it is known that it induces sympathetic activation [40], leading to lower volumes of a less fluid saliva. Besides AQP-5, other important mediators had been reported to play an important role in the mechanism of salivary secretion. To further analyze the molecular mechanism underlying salivation and hypoxia, HIF-1 $\alpha$ was 


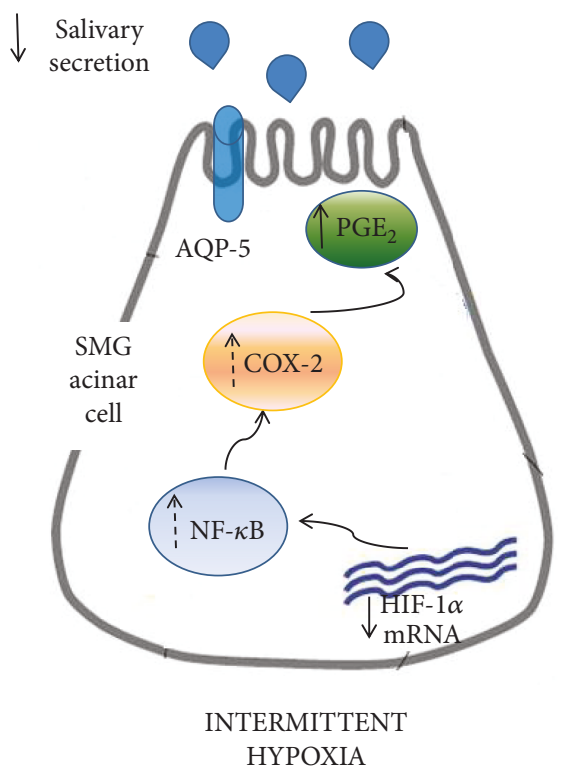

(a)

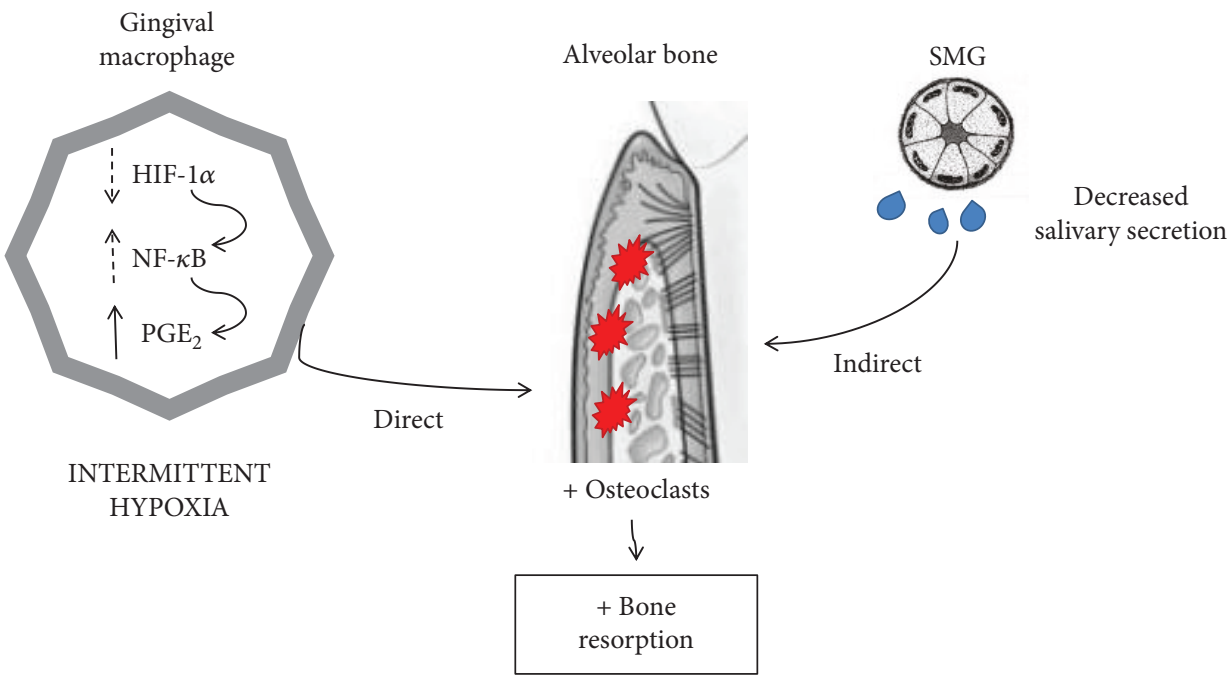

(b)

Figure 8: Proposed mechanism that leads to hyposalivation (a) and alveolar bone resorption (b) during exposure to intermittent hypoxia. The schemes contain the molecular mediators analyzed in this study ( $\mathrm{PGE}_{2}$, HIF- $1 \alpha$, and AQP-5: full arrow). However, multiple factors not included in the study participate in salivary secretion and alveolar bone metabolism, such as NF- $\kappa \mathrm{B}$ and COX-2 (dotted arrow). We hypothesize that more degradation of HIF- $1 \alpha$ due to the intermittent normoxic periods in the CIH group would be related with upregulation of NF- $\kappa \mathrm{B}$, leading to higher concentrations of $\mathrm{PGE}_{2}$, which is associated with lower levels of saliva and osteoclast genesis and activity. Furthermore, the decreased levels of saliva would constitute an indirect mechanism which increases alveolar bone resorption.

assessed in SMG. This transcription factor plays an integral role in the cellular adaptation to low $\mathrm{O}_{2}$ concentrations, being essential for immunological responses, vascularization, and anaerobic metabolism [41]. In this study, an increased localization of HIF- $1 \alpha$ in SMG of animals exposed continuously to hypoxia compared to intermittent exposure was shown. This could be due to the less time of exposure in the $\mathrm{CIH}$ group, which would induce more degradation of this transcription factor compared to the animals that spend longer periods under hypoxia $(\mathrm{CCH})$ [42]. The increased catabolism of HIF- $1 \alpha$ in $\mathrm{CIH}$ would mean less transcription of genes needed for the acclimation process, leading to a worse coordinated response to ensure the proper glandular function. It has been established that the activation of HIF$1 \alpha$ was related with less inflammatory state mediated by downregulation of $\mathrm{NF}-\kappa \mathrm{B}$ activation in periapical tissue [43], so we think that the NF- $\kappa$ B molecular pathway could be downregulated in the submandibular gland of $\mathrm{CCH}$ animals, enabling a better response to hypoxia (Figure 8). Furthermore, dental stem cells with overexpression of HIF- 
$1 \alpha$ had been shown to have a longer lifespan due to NK-lysis resistance [44], which reinforces the concept of this transcription factor being necessary for cellular health and survival. Contrary to our hypothesis, when assessed by PCR, we found similar levels of HIF- $1 \alpha$ mRNA in SMG of CIH and $\mathrm{CCH}$ groups. However, this does not rule out the possibility of less HIF- $1 \alpha$ in the glands of $\mathrm{CIH}$ as posttranscriptional changes on the protein expression and localization could take place. At the histological level, parenchyma and stromal architecture should be taken into consideration to fully evaluate gland morphology. In this study, serous and mucous acini as well as intralobular and secretory ducts showed a normal structure when observed under an optic microscope. Many authors have analyzed submandibular gland histoarchitecture in different animal models where salivary flow was decreased, and none of them have reported changes in the organ assessed by routine histological methods [22, 45]. Nevertheless, ultrastructural mechanisms which cannot be observed by optic microscopy could be playing a role in this experimental model and could explain the alterations in glandular function. In this study, transmission electron microscopy was employed to further analyze SMG morphology. Irregular secretory granules along with some apoptotic nuclei were found in cells of acini and intercalated ducts of $\mathrm{CIH}$ animals, whereas these alterations were not observed in the $\mathrm{CCH}$ group. These findings could indicate that not only saliva volume but also its quality might be affected under intermittent exposure, as secretory granules contain biologically active molecules that are crucial to ensuring saliva functions.

Regarding periodontal status in hypoxic rats, we found cortical bone loss due to hypoxia only in the lingual side of the mandible, with no effect at the buccal side. Interradicular bone loss was observed only due to $\mathrm{CIH}$ exposition, and this correlated with enhanced levels of CTX-I, a marker of collagen degradation due to increased bone resorption. Intermittent exposition to hypoxia would seem responsible for the increase in the content of $\mathrm{PGE}_{2}$ in gingival tissue, a potent stimulator of bone resorption, which would constitute a possible molecular mechanism that could explain higher osteoclast activity in this group. Besides this direct effect of hypoxia on osteoclast, it has been demonstrated that low levels of oxygen were capable of suppressing periodontal ligament cell migration and proliferation via the $\mathrm{Wnt} / \beta$-catenin signaling pathway [46], showing the intricate interplay between different periodontal tissues and molecular mechanisms of damage under hypoxic conditions. It is worth mentioning that we did not observe evidence of an ongoing inflammatory response in this experimental model, as evidenced by the absence of inflammatory infiltrate in soft tissue surrounding the teeth. This finding, together with the fact that interradicular bone resorption seemed to occur at the expense of bone marrow expansion, leads us to believe that hypoxia does not induce alveolar bone resorption though the activation of the innate immunity as it would happen in periodontal disease, but the bone resorption observed herein could be associated with an acclimation mechanism where hypoxia stimulates bone marrow expansion, as it happens normally in long bones [47]. The decreased salivary secretion would also contribute as an indirect mechanism with the alveolar bone loss observed under hypoxia, as situations with impaired saliva production had been related with increased values of CEJ-AC distance [6]. This may be explained by the fact that low salivary volume induces higher risk of oral infection due to decreased antimicrobial products, secretory immunoglobulin A, and salivary growth factors.

\section{Conclusions}

The different conditions through which animals are exposed to hypoxic stress appear to differentially activate cellular responses discussed herein. Animals exposed intermittently to hypoxia show worse SMG function than the ones submitted continuously, and this correlated with detrimental periodontal status in $\mathrm{CIH}$. These findings were associated with lower immunorreactivity of HIF- $1 \alpha$ and higher levels of $\mathrm{PGE}_{2}$, both at SMG and gingival levels, which suggest a negative role of this inflammatory mediator during hypoxic acclimation. Besides, our study suggests a distinct phenotypical variation in both experimental conditions that involves ultrastructural changes in SMG. Understanding whether a hierarchy among these two types of hypoxic response mechanisms exists and which are the precise timing and conditions of each mechanism to be activated will improve the knowledge of the biochemical mechanisms underlying hypoxia in oral tissues. This may eventually contribute to shedding light into the processes that regulate salivary gland adaptation and to finding therapeutics to treat the decreased salivary flow, improving in that way oral health.

\section{Data Availability}

The data used to support the findings of this study are included within the article.

\section{Conflicts of Interest}

All the authors declared having no conflict of interest.

\section{Acknowledgments}

This study was funded by UBACYT project 2016, $\mathrm{N}^{\circ}$ 20020150100006BA (Universidad de Buenos Aires, Argentina) and CONICET project 2012-2014, $\mathrm{N}^{\circ}$ PIP076. The authors want to thank Prof. Dr. Paul Fisch and MD. José Villacorta Hidalgo, from the Pathology Institute of the University of Freiburg, Germany, for their contribution and guidance during the immunohistochemistry experiments.

\section{References}

[1] M. W. J. Dodds, D. A. Johnson, and C.-K. Yeh, "Health benefits of saliva: a review," Journal of Dentistry, vol. 33, no. 3, pp. 223-233, 2005.

[2] M. D. Forde, S. Koka, S. E. Eckert, A. B. Carr, and D. T. Wong, "Systemic assessments utilizing saliva: part 1 general considerations and current assessments," The International Journal of Prosthodontics, vol. 19, no. 1, pp. 43-52, 2006. 
[3] A. Lomniczi, C. Mohn, A. Faletti et al., "Inhibition of salivary secretion by lipopolysaccharide: possible role of prostaglandins," American Journal of Physiology-Endocrinology and Metabolism, vol. 281, no. 2, pp. E405-E411, 2001.

[4] M. Amer, J. C. Elverdin, J. Fernandez-Solari, V. A. Medina, A. P. Chiarenza, and M. I. Vacas, "Reduced methacholineinduced submandibular salivary secretion in rats with experimental periodontitis," Archives of Oral Biology, vol. 56, no. 5, pp. 421-427, 2011.

[5] J. C. Atkinson, M. Grisius, and W. Massey, "Salivary hypofunction and xerostomia: diagnosis and treatment," Dental Clinics of North America, vol. 49, no. 2, pp. 309-326, 2005.

[6] M. I. Vacas, M. Amer, A. P. Chiarenza, M. A. Luchelli, P. M. Mandalunis, and J. C. Elverdin, "Influence of submandibulectomy on alveolar bone loss in rats," Journal of Periodontology, vol. 79, no. 6, pp. 1075-1080, 2008.

[7] S. Muthuraju and S. Pati, "Effect of hypobaric hypoxia on cognitive functions and potential therapeutic agents," Malaysian Journal of Medical Sciences, vol. 21, pp. 41-45, 2014.

[8] J. G. Farias, D. Jimenez, J. Osorio, A. B. Zepeda, C. A. Figueroa, and V. M. Pulgar, "Acclimatization to chronic intermittent hypoxia in mine workers: a challenge to mountain medicine in Chile," Biological Research, vol. 46, no. 1, pp. 59-67, 2013.

[9] P. Siques, Á. L. L. de Pablo, J. Brito et al., "Nitric oxide and superoxide anion balance in rats exposed to chronic and long term intermittent hypoxia," BioMed Research International, vol. 2014, Article ID 610474, 10 pages, 2014.

[10] A. H. Arestegui, R. Fuquay, J. Sirota et al., "High altitude renal syndrome (HARS)," Journal of the American Society of Nephrology, vol. 22, no. 11, pp. 1963-1968, 2011.

[11] G. L. Semenza, "Hypoxia-inducible factors in physiology and medicine," Cell, vol. 148, no. 3, pp. 399-408, 2012.

[12] C. Michiels, "Physiological and pathological responses to hypoxia," The American Journal of Pathology, vol. 164, no. 6, pp. 1875-1882, 2004.

[13] H. K. Eltzschig and P. Carmeliet, "Hypoxia and inflammation," The New England Journal of Medicine, vol. 364, no. 7, pp. 656-665, 2011.

[14] P. Maiti, S. B. Singh, A. K. Sharma, S. Muthuraju, P. K. Banerjee, and G. Ilavazhagan, "Hypobaric hypoxia induces oxidative stress in rat brain," Neurochemistry International, vol. 49, no. 8, pp. 709-716, 2006.

[15] J. C. Elverdin, A. P. Chiarenza, A. B. Frid, and M. J. Giglio, "Effects of chronic hypoxia on the secretory responses of rat salivary glands," Archives of Oral Biology, vol. 40, no. 5, pp. 459-462, 1995.

[16] N. Sugimoto, K. Matsuzaki, H. Ishibashi et al., "Upregulation of aquaporin expression in the salivary glands of heat-acclimated rats," Scientific Reports, vol. 3, no. 1, p. $1763,2013$.

[17] A. R. Terrizzi, J. Fernandez-Solari, C. M. Lee et al., “Alveolar bone loss associated to periodontal disease in lead intoxicated rats under environmental hypoxia," Archives of Oral Biology, vol. 58, no. 10, pp. 1407-1414, 2013.

[18] C. Jian, C. Li, Y. Ren et al., "Hypoxia augments lipopolysaccharide-induced cytokine expression in periodontal ligament cells," Inflammation, vol. 37, no. 5, pp. 14131423, 2014.

[19] Y.-H. Tan, G. Zhang, Y. Kong, Y.-Q. Gao, J. Lv, and X. Wu, "Periodontitis in a high-altitude hypoxic environment through rat model simulation," Asian Journal of Animal and Veterinary Advances, vol. 8, no. 4, pp. 593-603, 2013.

[20] N. Lüneburg, P. Siques, J. Brito et al., "Long-term chronic intermittent hypobaric hypoxia in rats causes an imbalance in the asymmetric dimethylarginine/nitric oxide pathway and ROS activity: a possible synergistic mechanism for altitude pulmonary hypertension?," Pulmonary Medicine, vol. 2016, Article ID 6578578, 9 pages, 2016.

[21] M. I. Conti, A. R. Terrizzi, C. M. Lee et al., "Effects of Lead exposure on growth and bone biology in growing rats exposed to simulated high altitude," Bulletin of Environmental Contamination and Toxicology, vol. 88, no. 6, pp. 1033-1037, 2012.

[22] C. A. Ossola, P. N. Surkin, C. E. Mohn, J. C. Elverdin, and J. Fernández-Solari, "Anti-inflammatory and osteoprotective effects of cannabinoid-2 receptor agonist HU-308 in a rat model of lipopolysaccharide-induced periodontitis," Journal of Periodontology, vol. 87, no. 6, pp. 725-734, 2016.

[23] C. E. Mohn, J. Fernandez-Solari, A. De Laurentiis, S. R. Bornstein, M. Ehrhart-Bornstein, and V. Rettori, "Adrenal gland responses to lipopolysaccharide after stress and ethanol administration in male rats," Stress, vol. 14, no. 2, pp. 216226, 2011.

[24] D. S. Bredt and S. H. Snyder, "Nitric oxide mediates glutamatelinked enhancement of cGMP levels in the cerebellum," Proceedings of the National Academy of Sciences, vol. 86, no. 22, pp. 9030-9033, 1989.

[25] C. A. Ossola, P. N. Surkin, A. Pugnaloni, C. E. Mohn, J. C. Elverdin, and J. Fernandez-Solari, "Long-term treatment with methanandamide attenuates LPS-induced periodontitis in rats," Inflammation Research, vol. 61, no. 9, pp. 941-948, 2012.

[26] M. da Silva Maia, S. D. Bicudo, C. C. Sicherle, L. Rodello, and I. C. S. Gallego, "Lipid peroxidation and generation of hydrogen peroxide in frozen-thawed ram semen cryopreserved in extenders with antioxidants," Animal Reproduction Science, vol. 122, no. 1-2, pp. 118-123, 2010.

[27] J. V. Hidalgo, P. Bronsert, M. Orlowska-Volk et al., "Histological analysis of gdT lymphocytes infiltrating human triplenegative breast carcinomas," Frontiers in Immunology, vol. 5, 2014.

[28] P. N. Surkin, S. L. Gallino, V. Luce, F. Correa, J. FernandezSolari, and A. De Laurentiis, "Pharmacological augmentation of endocannabinoid signaling reduces the neuroendocrine response to stress," Psychoneuroendocrinology, vol. 87, pp. 131-140, 2018.

[29] J. M. Crawford, M. A. Taubman, and D. J. Smith, "The natural history of periodontal bone loss in germfree and gnotobiotic rats infected with periodontopathic microorganisms," Journal of Periodontal Research, vol. 13, no. 4, pp. 316-325, 1978.

[30] A. R. Terrizzi, J. Fernandez-Solari, C. M. Lee, M. I. Conti, and M. P. Martínez, "Deleterious effect of chronic continuous hypoxia on oral health," Archives of Oral Biology, vol. 72, pp. 1-7, 2016.

[31] L. Busch, V. Miozza, L. Sterin-Borda, and E. Borda, "Increased leukotriene concentration in submandibular glands from rats with experimental periodontitis," Inflammation Research, vol. 58, no. 7, pp. 423-430, 2009.

[32] P. Pilardeau, J.-P. Richalet, P. Bouissou, J. Vaysse, P. Larmignat, and A. Boom, "Saliva flow and composition in humans exposed to acute altitude hypoxia," European Journal of Applied Physiology and Occupational Physiology, vol. 59, no. 6, pp. 450-453, 1990. 
[33] R. C. Li, B. W. Row, E. Gozal et al., "Cyclooxygenase 2 and intermittent hypoxia-induced spatial deficits in the rat," American Journal of Respiratory and Critical Care Medicine, vol. 168, no. 4, pp. 469-475, 2003.

[34] G. Daneau, R. Boidot, P. Martinive, and O. Feron, "Identification of cyclooxygenase-2 as a major actor of the transcriptomic adaptation of endothelial and tumor cells to cyclic hypoxia: effect on angiogenesis and metastases," Clinical Cancer Research, vol. 16, no. 2, pp. 410-419, 2010.

[35] G. Wu, A. P. Mannam, J. Wu et al., "Hypoxia induces myocyte-dependent COX-2 regulation in endothelial cells: role of VEGF," American Journal of Physiology-Heart and Circulatory Physiology, vol. 285, no. 6, pp. H2420-H2429, 2003.

[36] P. N. Correia, G. H. Carpenter, K. L. Paterson, and G. B. Proctor, "Inducible nitric oxide synthase increases secretion from inflamed salivary glands," Rheumatology, vol. 49, no. 1, pp. $48-56,2010$.

[37] C. Delporte and S. Steinfeld, "Distribution and roles of aquaporins in salivary glands," Biochimica et Biophysica Acta (BBA) - Biomembranes, vol. 1758, no. 8, pp. 1061-1070, 2006.

[38] Y. Ishikawa, G. Cho, Z. Yuan, N. Inoue, and Y. Nakae, “Aquaporin-5 water channel in lipid rafts of rat parotid glands," Biochimica et Biophysica Acta (BBA) - Biomembranes, vol. 1758, no. 8, pp. 1053-1060, 2006.

[39] T. Higashida, C. W. Kreipke, J. A. Rafols et al., "The role of hypoxia-inducible factor- $1 \alpha$, aquaporin-4, and matrix metalloproteinase-9 in blood-brain barrier disruption and brain edema after traumatic brain injury," Journal of Neurosurgery, vol. 114, no. 1, pp. 92-101, 2011.

[40] R. Hainsworth, M. J. Drinkhill, and M. Rivera-Chira, "The autonomic nervous system at high altitude," Clinical Autonomic Research, vol. 17, no. 1, pp. 13-19, 2007.

[41] J. E. Ziello, I. S. Jovin, and Y. Huang, "Hypoxia-inducible factor (HIF)-1 regulatory pathway and its potential for therapeutic intervention in malignancy and ischemia," The Yale Journal of Biology and Medicine, vol. 80, no. 2, pp. 51-60, 2007.

[42] S. K. Hota, K. Barhwal, S. B. Singh, and G. Ilavazhagan, "Differential temporal response of hippocampus, cortex and cerebellum to hypobaric hypoxia: a biochemical approach," Neurochemistry International, vol. 51, no. 6-7, pp. 384-390, 2007.

[43] K. Hirai, H. Furusho, K. Hirota, and H. Sasaki, "Activation of hypoxia-inducible factor 1 attenuates periapical inflammation and bone loss," International Journal of Oral Science, vol. 10, no. 2, article 12, 2018.

[44] V. G. Martinez, I. Ontoria-Oviedo, C. P. Ricardo et al., "Overexpression of hypoxia-inducible factor 1 alpha improves immunomodulation by dental mesenchymal stem cells," Stem Cell Research \& Therapy, vol. 8, no. 1, p. 208, 2017.

[45] J. P. Prestifilippo, J. Fernández-Solari, D. J. Martinel Lamas et al., "Pharmacological targeting of histamine $\mathrm{H} 4$ receptor in periodontal disease," Oral Diseases, vol. 22, no. 5, pp. 423429, 2016.

[46] Z. Xiao, Y. Han, Y. Zhang, and X. Zhang, "Hypoxia-regulated human periodontal ligament cells via $\mathrm{Wnt} / \beta$-catenin signaling pathway," Medicine, vol. 96, no. 16, article e6562, 2017.

[47] K. Takubo, N. Goda, W. Yamada et al., "Regulation of the HIF1alpha level is essential for hematopoietic stem cells," Cell Stem Cell, vol. 7, no. 3, pp. 391-402, 2010. 


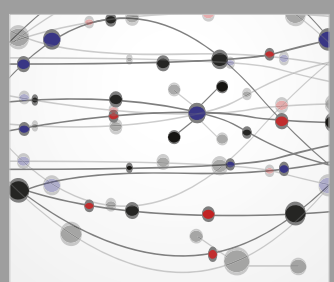

The Scientific World Journal
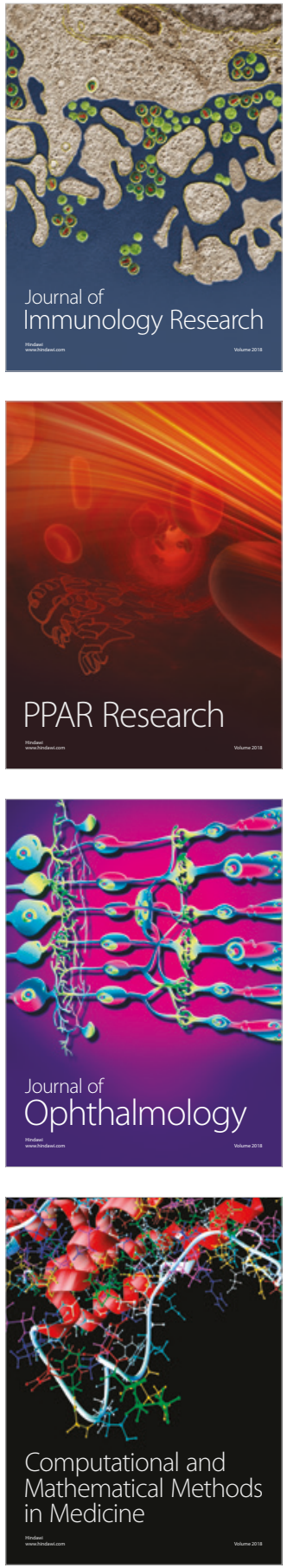

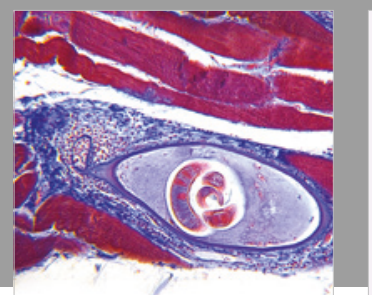

Gastroenterology Research and Practice

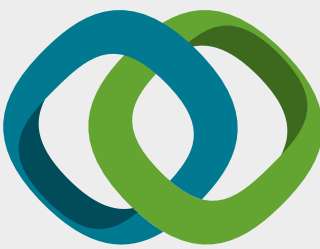

\section{Hindawi}

Submit your manuscripts at

www.hindawi.com
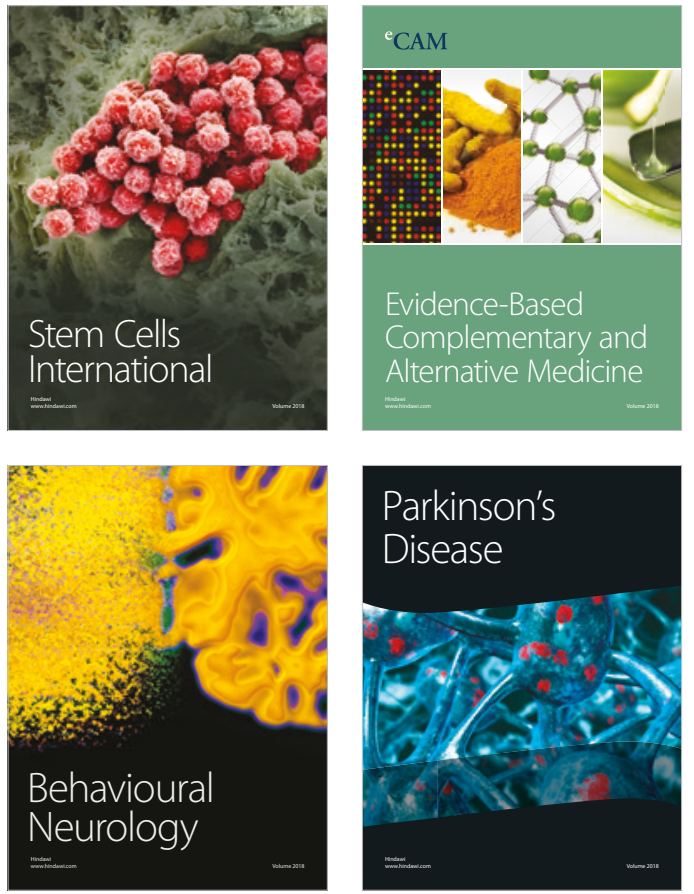

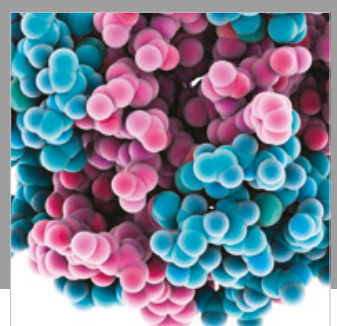

ournal of

Diabetes Research

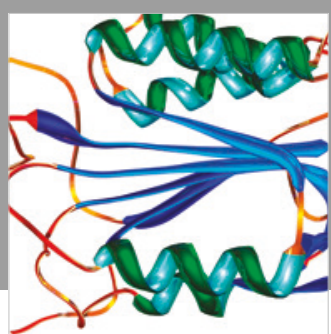

Disease Markers
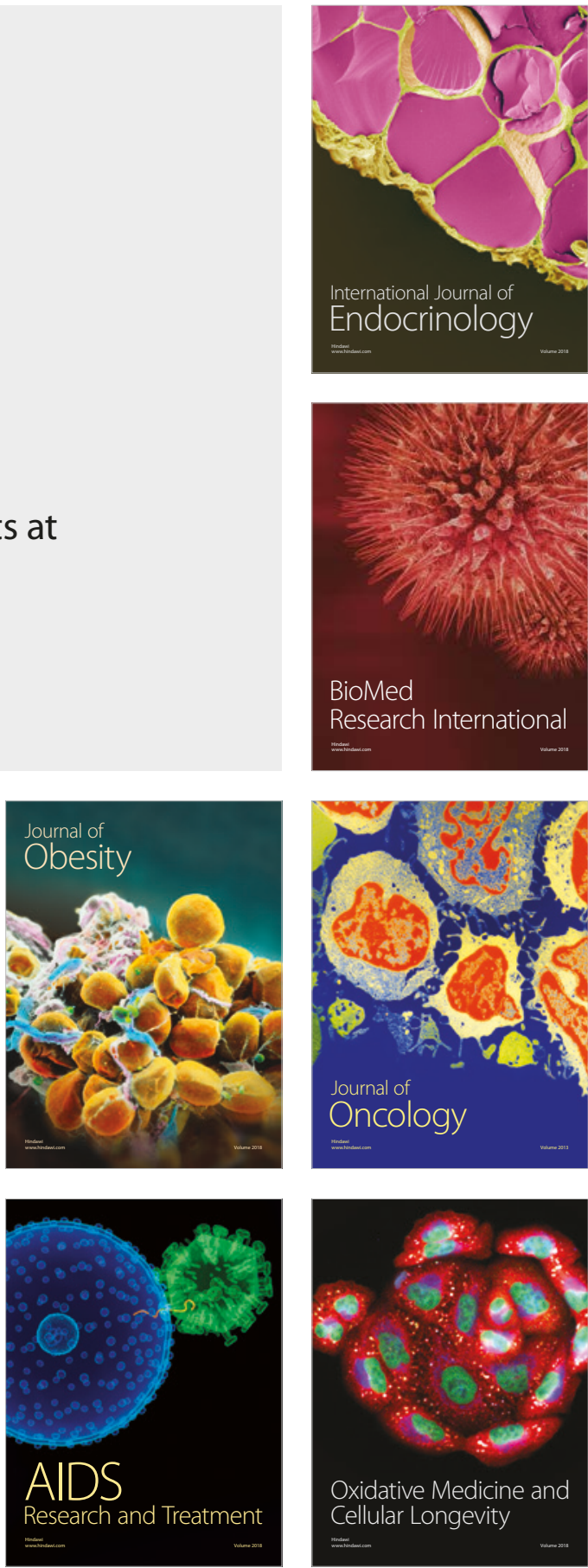